\title{
RESEARCH ON IMPLEMENTATION ORTHOPEDIC PROSTHESES ANKLE BY THE PROCESS RAPID PROTOTYPING
}

\author{
Drd. Eng. Ștefan-Cătălin Popescu1, Prof. Dr. Eng. Gheorghe I. Gheorghe², \\ Prof. Dr. Eng. Octavian Donţu ${ }^{3}$ \\ ${ }^{13}$ Politehnica University of Bucharest \\ Splaiul Independenţei nr. 313, sector 6, Bucharest \\ ${ }^{2}$ The National Institute of Research and Development in Mechatronics and \\ Measurement Technique, Sos. Pantelimon, No. 6-8, Sector 2, Bucharest, Romania \\ popescu.stefancatalin@yahoo.com
}

\begin{abstract}
It presents the advantages it offers rapid prototyping for making orthopaedic prostheses compared to current manufacturing processes thereof. Dimensional reconstruction and anatomic ankle system modelling techniques based on the analysis and processing of images, graphic representations using 3D anatomical model of ankle and using this model for implementation ankle prosthesis $3 \mathrm{D}$ printing techniques.
\end{abstract}

Keywords: 3D Printing Techniques, Ankle Prostheses, 3D Modelling.

\section{Introduction}

Rapid prototyping 3D is based on the decomposition of thin cross-sectional layers, followed by physical forming of the layers and their stacking 'layer by layer'. Using 3D computer models is particularly important in realizing the concept of creating layered objects, but other technologies, such as laser systems and powerful computers have helped define the technology [1].

This technology produces very complex 3D structures [2].

Rapid prototyping technologies (technologies for rapid prototyping and manufacturing Rapid Prototyping - RP) are used to achieve a prostheses of the ankle by the addition of material.

The selective laser sintering process (Selective Laser Sintering - SLS) is currently one of the most versatile on the market, thanks in part to the large number of available materials [3].

\section{Laser Sintering Processes}

Processes for laser sintering of powders is based on the property of having a greater contact area than the solids, and that each free energy of the system tends towards a minimum.

In consequence of neigh boring particles will be melted early only on the surface, and the total area will decrease by bonding particle surfaces. The process of sintering is best described as the interaction of the viscosity of the particle at the beginning of fusion and surface tension. Both depend on the material and temperature [4].

By heating the particles at a high temperature and applying at the same time, a high pressure between neighbouring particles will form bridges, thus joining them.

Laser Sintering used as a rapid prototyping process will not depend on pressure and time as in the conventional sintering.

A thermal activation takes place of the particles for a short period of time. Particles in the bed of powder are free, they are rendered selectively merging the laser beam in such a layer. In fact, this is a partial melting and solidification process called selective laser sintering or laser sintering liquid [5].

Since classical conditions to have a high pressure and have a greater dwell time should no longer be met, laser sintering involves no diffusion but an early stage melting or fusion of the powder particles.

The selective laser sintering process, the powder is selectively sintered or melted by the infrared laser source.

Once a layer is finished, the powder bed down to a thickness of a layer and a new layer of powder is deposited and the process continues.

No tools required support as sintered powder material support piece.

Finally, the finished work-piece surface is slightly rough to the touch.

Currently there are seven materials available for this system, including the two materials in order to manufacture: Duraform materials (nylon), Glass Filled Duraform Fine Nylon, True form elastomeric Copper Polyamide, HSS and Sand Form. 
Selective laser sintering process advantages are: there is a wide range of materials, good accuracy, can achieve large pieces.

The disadvantages of the process are related to the high cost of laser installation and poor surface roughness of the obtained [6].

\section{Stages of a Total Ankle Prosthesis}

Design and 3D modelling technologies, resulting in a large number of software pack-ages adapted to be used [7]. After exporting a file from a 3D modelling package, in cross-section is reduced digital object, or layers, creating a 2D image for each $0.1016 \mathrm{~mm}$ (0.004") slice along the z-axis. These can be viewed coloured sections and labelled. Software sent to the embodiment of the 2D cross-sectional images through a network [8], [9].

The main phases of a total ankle prosthesis are shown in Figure 1.

In the first phase identified the patient's body that needs the device prosthesis, then taken all specific patient, these data are stored in a database to obtain a digital image of surfaces including patient anatomy in the area of interest.

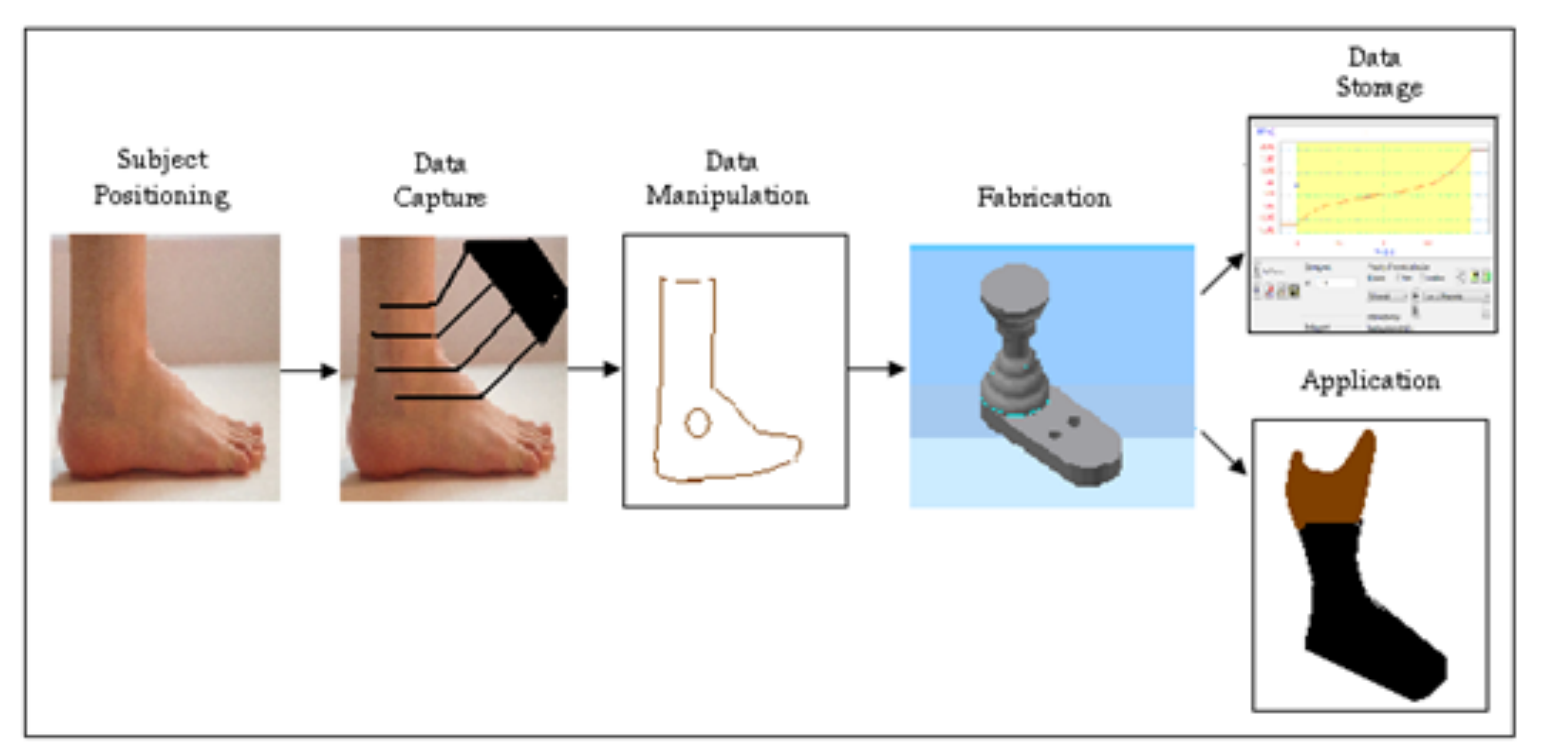

Figure 1: The main phases of a total ankle prosthesis

Making database allows data to be stored in multiple tables linked via index data. This allows quick and easy viewing and data processing. Once in the database, the information can be manipulated and viewed in various ways, such as sorting or special queries and reports. When creating the database can use Microsoft Office Access application [10], [11].

Relationships between database tables and connections in common areas (same name, same length, same properties). Databases reduces the time it takes to develop technical documentation and product launch in the manufacturing process and allow immediate access to all information necessary for a product, regardless of its complexity.

The raw material used for Rapid Prototyping technologies may be in liquid, solid or powder form. Processes using liquid raw materials are divided into two groups.

In the first group are processes which use liquid polymer to be solidified at the impact of the laser beam or the light of ultraviolet lamps (such as stereo lithography - SLA) or by heating (thermal polymerization), and the second group is formed by processes which are based on the melting, deposition and solidification of these technologies allows the use of plastics or metal (such as fused deposition modelling - FDM).

Other processes using powdered starting material. The powder particles may be sintered to the desired shape (Selective Laser Sintering - SLS) or may be bonded using a binding agent directed only at the points necessary for a section (3D printing).

The solids are generally in the form of thin films, and the pieces will be made by gluing or welding of foils in layers followed by cutting the outline of the inside and outside of a section by means of a laser beam (manufacture of layered piece - LOM ).

There Rapid Prototyping processes that build the three-dimensional part directly, but most technologies running track of layers builtdimensional (2D) superimposed. For this based on the solid model of the part sectioned in the horizontal plane of the layers piece spaced a few tenths of a millimetre [12], [13].

Modelling anatomical ankle biomechanical system is based on the techniques of mechanical and 
mathematical calculation to obtain the information necessary to design and implement prosthesis.

The first step is defining data biomechanical kinematics system for determining dynamic parameters.

As input data to the system dynamic balance equations for determining the internal reaction forces and moments that cause system movements are used anthropometric parameters, the dynamic parameters, and kinematic parameters of the body segments.

It requires the use of special conditions:

- the ankle is divided into segments considered in the concentrated mass of solid bodies with their centre of gravity;

- anthropometric parameters of segments are considered constant during the journey;

- friction with the air is minimized;

- ground friction forces and the joints are considered null;

- speed of the entire system is considered constant;

- walking is considered a repetitive cycle and symmetrical for both legs.

To determine reaction forces and reactive moment of the ankle joint is necessary to know:

- the internal forces exerted in the muscles, tendons and bone surfaces in contact between;

- the points of insertion of the muscles;

- distances between muscle insertion points and centre of rotation of the ankle.

Since these requirements are almost impossible to determine and greatly complicates the model for determining the forces of reaction and when muscular net reduction technique using forces. Construction of the model can be made directly in 3D or $2 \mathrm{D}$ successive sections.
In this case, the CAD model of the part is cut in number of horizontal sections, spaced a few tenths of a millimetre.

The first sections are processed sections below, created first, adding them successively over the next until it reaches the last section.

Creating sections can be either point to point or layer by layer.

Most systems use scanning manufacture of the solid layer, continuous or discontinuous, and solidifying the material point by point.

Production of models and prototypes using rapid prototyping geometry requires that the product is available as a 3D data record.

This is most often done through a virtual model made in a 3D CAD system.

Information flow is divided into two parts: one serves design, which is made by CAD software program, and the second part serves the prototyping device that needs specialized software [14], [15].

Finite element numerical analysis assembly was required due to the static behaviour of complex structure, conventional calculations impossible to evaluate the resistance and was used to solve the problem of the finite element method, through the invention. Evaluation of the stress, strain and designed contact elements, static analysis was performed by structural assembly [14].

The numerical analysis applies to all the static finite element is designed as a first step the design and assembly of all the materials involved in the analysis of the declaration [15] [16].

After assigning the materials for the components of the assembly, the next step was to declare the contacts of the elements.

This operation was performed automatically identifying Inventor surfaces in physical contact, and showing their connection, Figure 2.

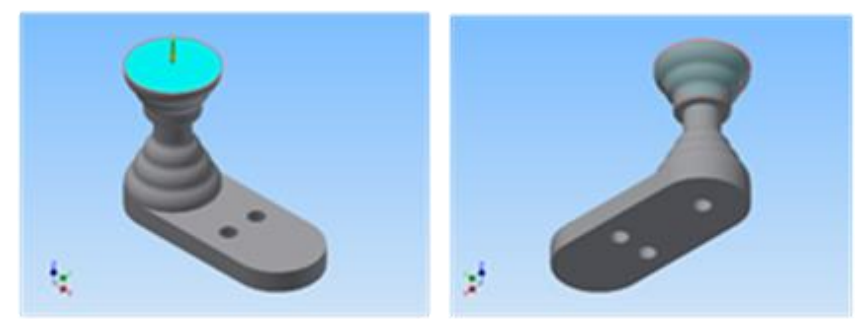

Figure 2: Selected Face(s)

Thus they were set 27 of contacts independent of the "bonded" (rigid fixation), Figure 3.

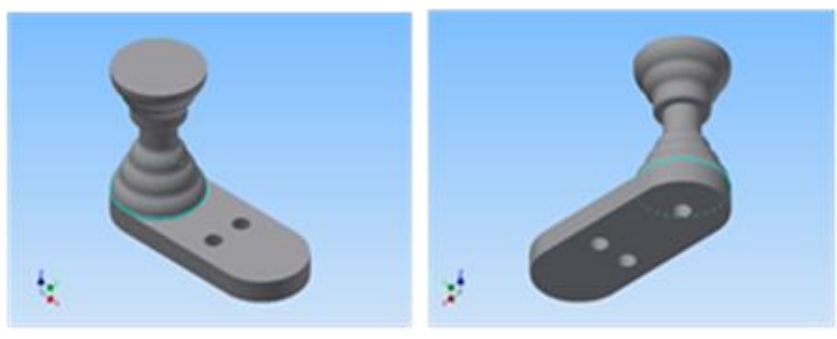

Figure 3: Contacts (Bonded) 
The next step of this analysis was the number of combinations of finite element mesh.

Discretization was done automatically using tetrahedral elements.
Step meshing was followed by the step of setting constraints and requests, Figure 4 , which is exerted on the assembly.
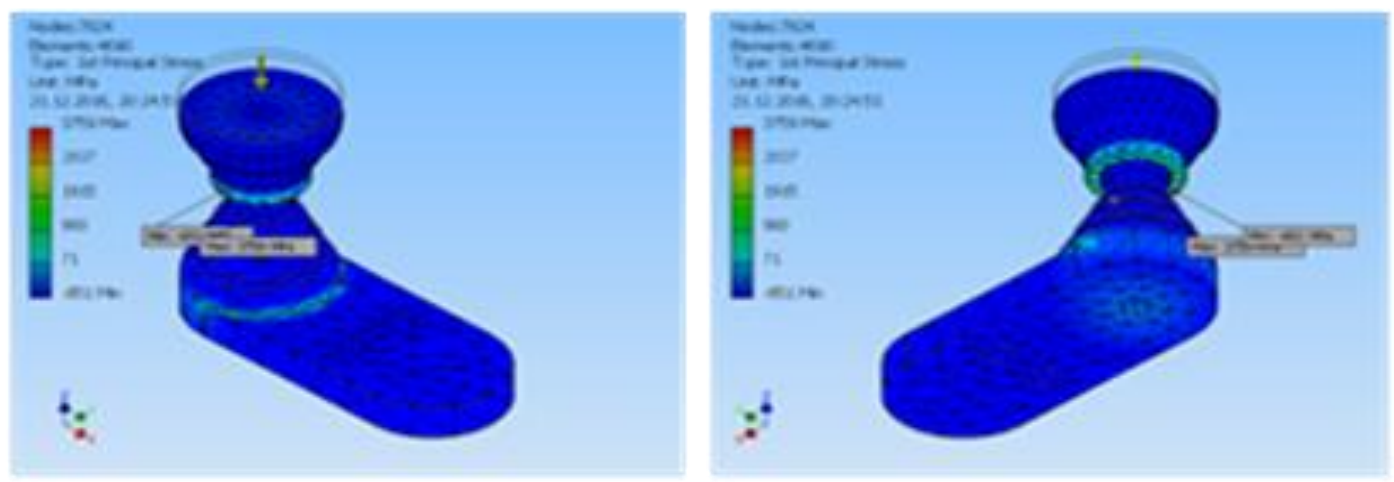

Figure 4: 1st Principal Stress

The assembly is subjected to the action of the two forces (force 1 and force 2), a moment of rotation and a movement on three axes: $\mathrm{XX}, \mathrm{XY}, \mathrm{XZ}$, and at the bottom, it is constrained by the recess (zero degrees of freedom) Figure 5, Figure 6, Figure 7.

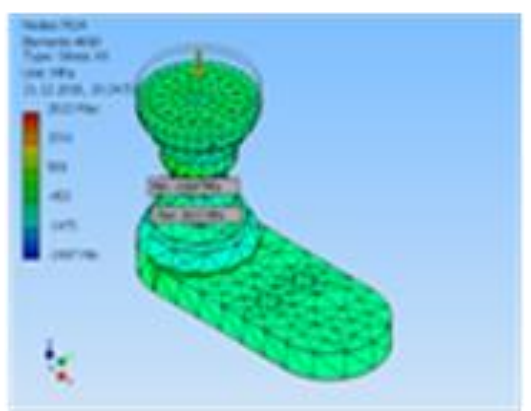

Figure 5: XX Stress

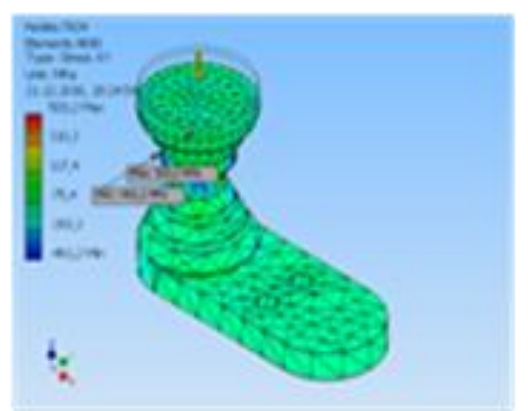

Figure 6: XY Stress

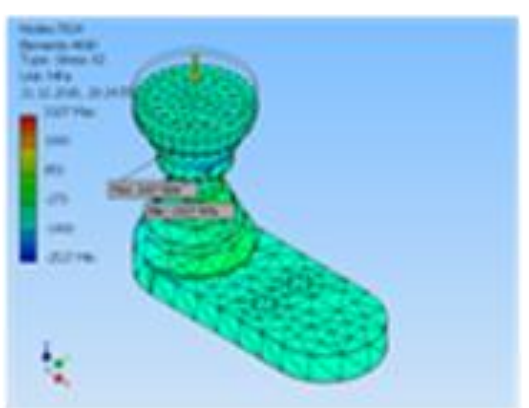

Figure 7: XZ Stress
Force 1 is the reaction force acting on the y-axis. Force 2 is the reaction force acting on the $\mathrm{X}$ axis.

The torque applied to the assembly, subjected to finite element analysis, is the moment which is exerted on the ankle support during the last phase of the foot on the ground.

Next are analyzed the displacements on the $x$ axis and the OZ axis, Figure 8, Figure 9 and Figure 10.

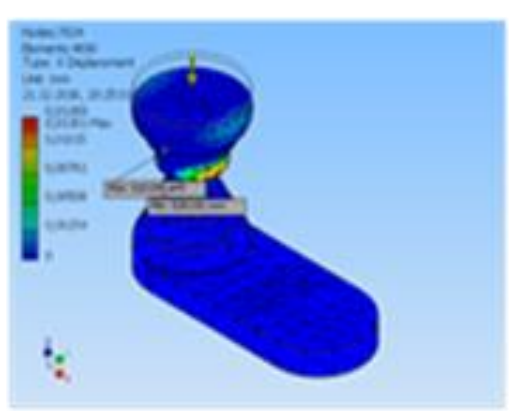

Figure 6: X Displacement

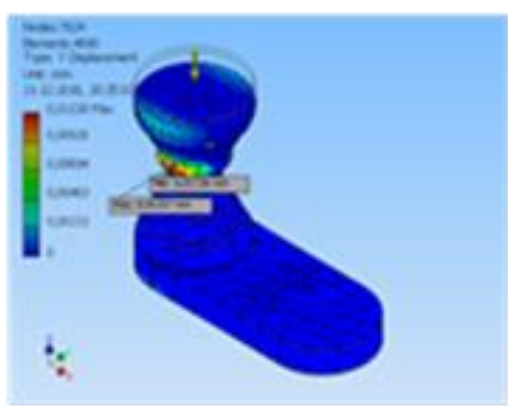

Figure 9: Y Displacement

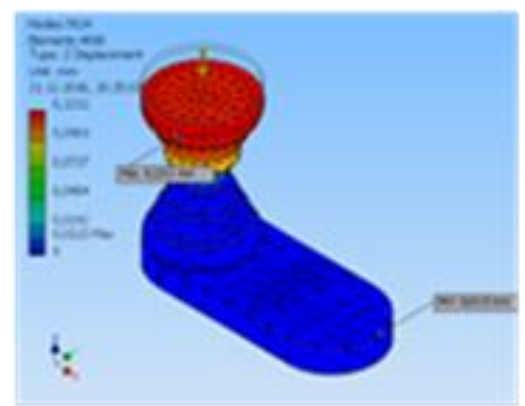

Figure 10: Z Displacement

The analysis results of the analysis of the results is shown in Table 1 and Table 2. 
Table 1. Centre of Gravity

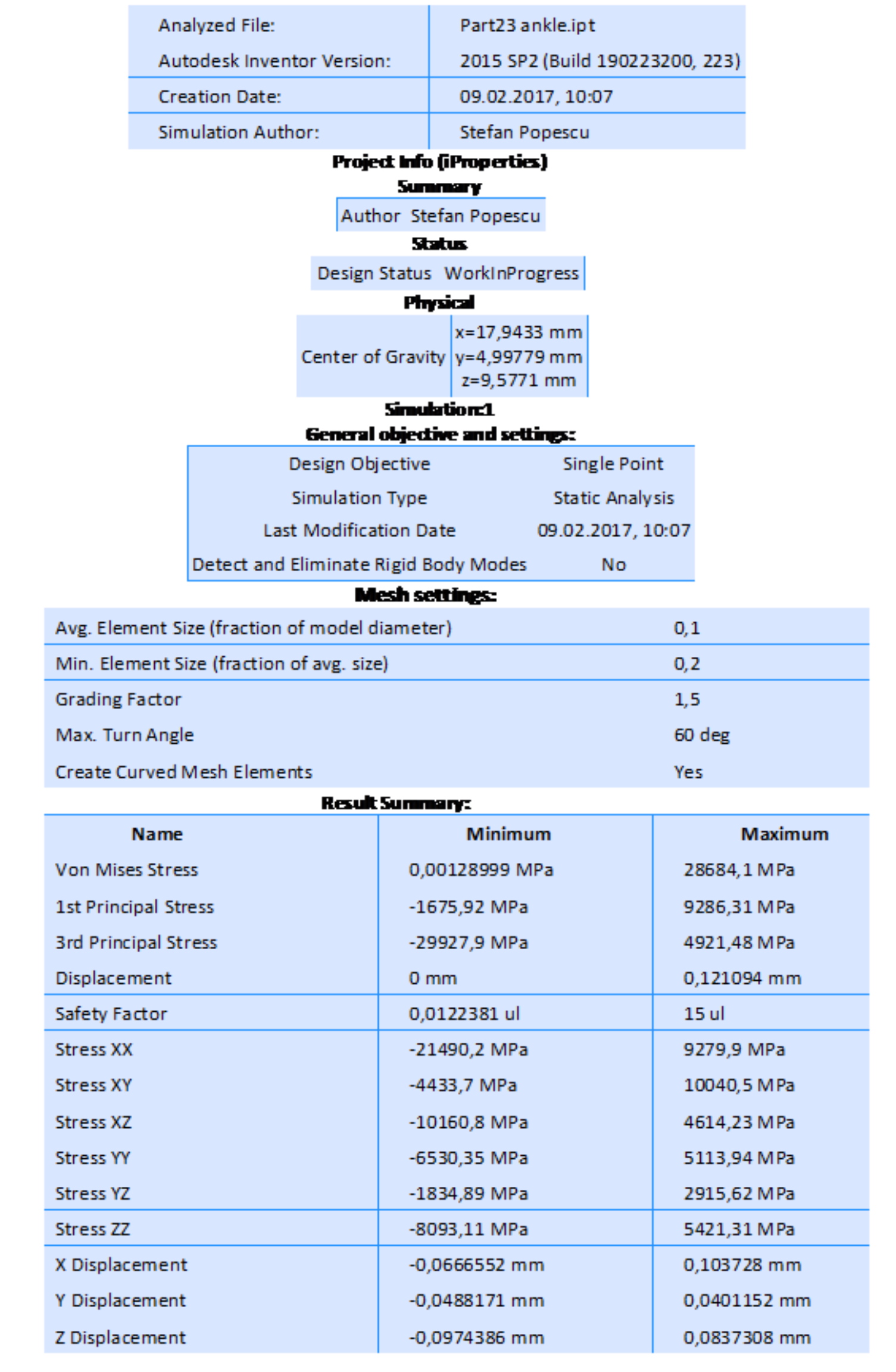




\begin{tabular}{|lll|}
\hline \multicolumn{1}{|c}{ Name } & \multicolumn{1}{|c|}{ Mesute Summary } \\
Equivalent Strain & $0,00000000756156 \mathrm{ul}$ & \multicolumn{1}{c|}{ Maximum } \\
\hline 1st Principal Strain & $-0,000128633 \mathrm{ul}$ & $0,0703322 \mathrm{ul}$ \\
3rd Principal Strain & $-0,136937 \mathrm{ul}$ & $0,00221156 \mathrm{ul}$ \\
Strain XX & $-0,0834303 \mathrm{ul}$ & $0,0298504 \mathrm{ul}$ \\
Strain XY & $-0,0281162 \mathrm{ul}$ & $0,0636717 \mathrm{ul}$ \\
\hline Strain XZ & $-0,0644344 \mathrm{ul}$ & $0,029261 \mathrm{ul}$ \\
\hline
\end{tabular}

The process of making the ankle prosthesis is shown in Figure 13.

A roller mechanism (2) spreads powder fed by a reciprocating platform construction.

The spreader an additional $30 \%$ of each coating powder to ensure complete coverage and density of the powder on the construction platform.

After applying a layer of powder, the binder is deposited on the specific area of the first section 3
Following receipt of the information on the next cross-section (4)

To remove the particulate matter in excess on the surface of the model is used a blower.

The operations are repeated, Figure 13 (5) and Figure $13(6)$ to obtain the projected piece $(7)$.

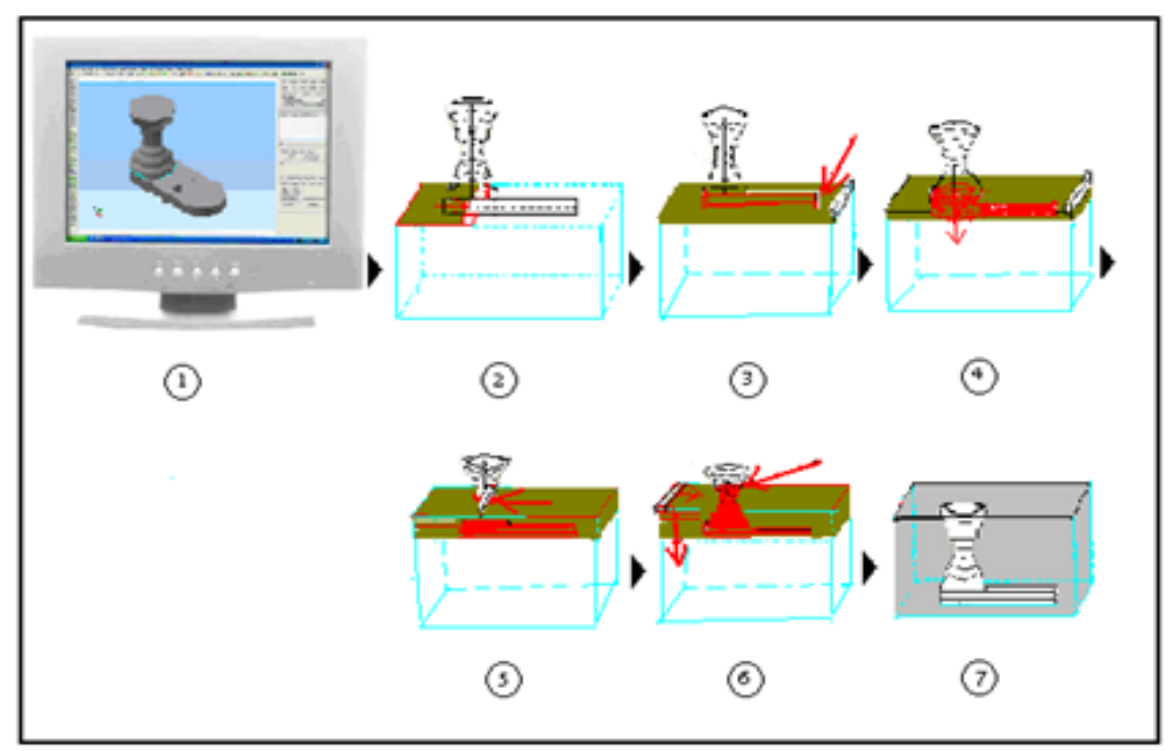

Figure 7: Printing process

\section{Conclusions}

I watched through the application of these technologies achieve in the short term a medical endoprosthesis.

Thus, it can test the installation and adjustments even before having the final product, thus eliminating any errors or problems that may arise, such as changing the stump due to bandaging incorrect or any postoperative complications.

Also in this phase, you can adjust the length of the sole (some patients prefer a shorter base) or the depth of the prosthesis, the cup edges, or the manner of fastening.

Thus, when the final hearing will be produced, it will just respond to patient needs.

At the same time, manufacturing time is significantly reduced because the prosthesis will be a pattern defined, specific and accurate in terms of shape, able to respond fully to individual patient requirements.

Using rapid prototyping processes in orthopaedic prostheses obtain an advantage for the quality of work, reducing cost and time of execution and in terms of meeting the needs of each patient. 


\section{References}

[1] Besnea, Daniel, Avram, M., Constantin, V., Spanu, A., Chivu, L.A: Additive micromanufacturing technologies for composite materials based on nanotubes and polymers, Romanian Review Precision Mechanics, Optics \& Mecatronics, Nr. 50/2016, ISSN 158-5982, pag. 16-19 (2016).

[2] Drstvensek, I., IhanHren, N., Strojnik, T., Brajlih, T., Valentin, B., Pogacar, V., Zupancis Hartner, T.: Applications of Rapid Prototyping in CranioMaxilofacial Surgery Procedures, International Journal of Biology and Biomedical Engineering, Issue 1, Volume 2, pp. 29-38.(2008).

[3] Alexander, H., Brunski, J.B., Cooper, S.L., Hench, L.L., Hergenrother, R.W., Hoffman, A.S., Kohn, J., Langer, R., Peppas, N.A., Ratner, B.D., Shalaby, S.W., Visser, S.A., Yannas, I.V.: An Introduction to Materials in Medicine, Academic Press, New York, (1996).

[4] Dolinsek, S., Kopac, J., Prodan, I.: Industrial applications with DMLS rapid tooling, V: International Manufacturing Leaders Forum, IMLF2005: proceedings, Adelaide, Australia, pp. 117 - 122(2005).

[5] Bell, W. H.: Modern practice in orthognatic and reconstructive surgery, W. B. Saunders Company, Philadelphia (1992).

[6] De Vleeschouwer, M.: The Usage of Medical Images for Creating Custom FE And CFD Models, Proceedings of the 1st International Conference on Additive Manufacturing, DAAAM International, (2007).

[7] Antonescu, D., Buga, M., Constantinescu I.: Method of calculation and experimental stress analysis techniques biomechanics (Metode de calcul şi tehnici experimentale de analiza tensiunilor în biomecanică), Ed.

[8] Batalu, D.: Implant design (Proiectarea implanturilor), U. P. Bucureşti, Curs (2007).

[9] Alexander, $\mathrm{H}$ and colab.: An Introduction to Materials in Medicine, Academic Press, New York(1996).
[10] Radu, C.: Application of computer graphics in a $3 \mathrm{D}$ reconstruction of human ankle, the 1 st International Conference «Computational Mechanics and Virtual Engineering» COMEC 2005, Braşov, ISBN 973-635-593-4(2005).

[11] Bergmann G., Graichen F., Rohlmann A.: Instrumentation of a hip joint prosthesis. In: Bergmann G, Graichen F, eds. Implantable Telemetry in Orthopedics, ISBN 3-927433-45-4, Berlin, 35-63(1990).

[12] Bannon, B. P., and Mild, E. E.: Titanium Alloys for Biomaterial Application: An Overview, Titanium Alloys in Surgical Implants, ASTM STP 796, American Society for Testing and Materials, pp. 7-15(1983).

[13] Ciobota, N.D.: Titanium and Titanium Alloys for Biomedical and Industry Applications, National Institute of Research and Development for Mechatronics and Measurement Technique, Bucuresti, International Conference 6th Workshop on European Scientific and Industrial Collaboration on promoting Advanced Technologies In Manufacturing WESIC'08, Bucharest 25-26 September (2008).

[14] Roşca, I., Radu, C.: On the design of the analytical ankle-foot model used to determine dynamic parameters during locomotion, 6th International DAAAM Baltic Conference INDUSTRIAL ENGINEERING, DAAAM 2008, Tallin, Estonia, ISBN 978-9985-59-783-5 (2008).

Roşca, I., Radu, C.: On a mechatronic system to determine dynamic parameters of human limb during locomotion used from artificial muscles and implant design, 6th International DAAAM Baltic Conference INDUSTRIAL ENGINEERING, DAAAM 2008, Tallin, Estonia, ISBN 978-998559-783-5 (2008).

[15] Iliescu, M., Nuțu, E., Georgescu, L.: Finite Element Method Simulation and Rapid Prototyping, Proceedings of the 8th WSEAS International Conference on Electric Power Systems, High Voltages, Electric Machines (POWER '08), pag. 257(2008). 